\title{
El Carnaval y el poder: Una muestra de contestación popular a las restricciones en una letrilla de 1828
}

\author{
ALBERTO RAMOS SANTANA \\ JOSE MANUEL FERNANDEZ TIRADO
}

Es corriente que cuando se habla de Carnaval se destaque la función liberadora, en lo social y en lo psicológico, que tiene la fiesta, indicando además que ninguna otra fiesta puede cubrir tales aspectos como los días de carnestolendas.

Esta interpretación reiterativa encaja perfectamente en las funciones de la fiesta hoy en día. Pero si rastreamos en el pasado empezaremos a encontrar otros rasgos que en la actualidad no se dan, o al menos no tienen la pureza e intensidad que tuvieron en tiempos pretéritos. En este sentido no cabe hablar actualmente de que el Carnaval rompe el orden social o enfrenta las clases.

Sin embargo, estas funciones se veían realzadas en épocas pasadas, y era, posiblemente, la esencia de la fiesta. Roger Callois (1) ha expuesto cómo la infracción de las reglas, la turbulencia y el frenesí destructor formaban parte de la fiesta. En el caso del Carnaval, la utilización del disfraz -elemento común, por otra parte, a muchas demostraciones festivas- da una mayor preponderancia a la inversión del orden de las cosas, a todo tipo de excesos, ya sea en la comida y bebida, como en lo erótico, y refuerza la posibilidad de ironizar y satirizar a la sociedad y a la autoridad.

Quizás lo que particulariza a la fiesta de Carnaval es que esa inversión de valores estaban en cierta medida establecidas, y así se convertían en una especie de vacuna previa -consistente en la permi-

(1) CALLOIS, Roger: L'bomme et lè sacré. París, 1963, 3.a ed. pp. 121-162. Confer: Asencio. Itinerario del entremés. Madrid, 1971, 2. a ed. pp. 251 y ss. 
sividad de todos los excesos- que se ponía antes de la represión moral de la Cuaresma y del regreso a la monotonía y al ritmo cotidiano.

Hay múltiples testimonios (podríamos citar entre los primeros Las églogas de antruejo o El libro de buen amor), de que las Carnestolendas, o lo que es lo mismo, los tres días previos al Miércoles de Ceniza, se celebraban con gran alegría y todo tipo de excesos y glotonerias, como desquite de los inmediatos ayunos cuaresmales.

A pesar de ese carácter de permisividad y de cierta institucionalización de la costumbre popular, la fiesta de la inversión de valores no podía estar bien vista por los detentadores del poder, que intentarán desde muy pronto prohibir las celebraciones o al menos limitarlas. Hemos escrito en alguna ocasión que la Historia del Carnaval es en gran medida la historia de su lucha por la supervivencia frente a las prohibiciones (2).

Ya Carlos I en 1523 prohibió "en absoluto" las máscaras (3). Y las autoridades eclesiásticas también pusieron bien pronto cuidado en estas celebraciones que alteraban el orden. Arturo Morgado ha destacado que en las Constituciones Sinodales de 1591 y en los Estatutos del Seminario de Cádiz de 1596, promulgadas ambas por el prelado Antonio Zapata y Cisneros contienen indicaciones para que los eclesiásticos y colegiales no bailaran ni cantaran ni se descompusieran como lo hacían los seglares durante las fiestas. Y en el primero de los documentos citados se indica que no salgan ni enmascarados ni de ninguna otra manera tapados (4).

Pero nunca la jerarquía o el poder -como trataremos de demostrar- han sido capaces de terminar con la fiesta, a pesar del interés y la constancia que han desarrollado para acabar con esa visión particular de la realidad que se da en Carnaval, y que es totalmente contrapuesta a la oficial. En algunas ocasiones la lucha ha sido tan dura que el propio poder ha renunciado ante la fortaleza de la fiesta popular.

Es lo que podemos deducir de un interesante documento que se guarda en el archivo de la parroquia de Santa Cruz de Cádiz. En un

(2) Véase: RAMOS SANTANA, Alberto: Historia del Carnaval de Cádiz. Cádiz, 1985.

(3) CARO BAROJA, Julio: El carnaval (Análisis bistórico cultural). Madrid, 1986, pp. 154-155. Caro Baroja, junto a las prohibiciones "nacionales" da una serie larga de prohibiciones locales.

(4) MORGADO GARCIA, Arturo: "La iglesia gaditana y el Carnaval durante el Antiguo Régimen. Algunas aportaciones documentales". Actas del IV Seminario del Carnaval. En prensa. 
acta matrimonial del día tres de marzo de 1636 se recoge: "El Sr. Provisor dispensó en todo por ser carnestolendas" (5).

Y unos años después, otro documento reconoce la impotencia del poder civil ante la celebración popular. Antonio Domínguez Ortiz ha reseñado una carta del general Mencos, fechada en Cádiz a siete de febrero de 1652, en la que se dice: "Las obras principales de mi capitana tengo acabadas, y si la Maestranza se hubiera reducido a trabajar estas Carnestolendas fuera cayendo con ella desde el lunes, pero es gente a quien no govierna la razón ni el respeto" (6). Como el propio profesor Domínguez Ortiz señalaba, se puede deducir de este testimonio que las fiestas del Carnaval estaban ya tan arraigadas en Cádiz que los obreros se negaban a trabajar en esos días pese a la urgencia y al poder de quien se lo exigía.

También entre el estamento eclesiástico se daba una notable desobediencia de las órdenes de las autoridades. En 1678, el clérigo de menores don Nicolás Aznar fue acusado de mantener relaciones adúlteras con una tal doña Antonia Gil Moreno "desde las Carnestolendas del año pasado que disfrazado de máscara entró en su casa a bailar y danzar y le dieron dulces y estuvieron hablando..." (7).

A partir del siglo XVIII se reiteran frecuentemente las prohibiciones relativas al Carnaval. Ya en 1716 se prohibieron los bailes de máscara, prohibición que se volvió a repetir -esta vez contra las máscaras en general- en febrero de 1745 (8).

Las prohibiciones generales eran remitidas a los municipios por parte de la corona. En las Actas Capitulares del Ayuntamiento gaditano se recogen varias de estas órdenes. Como ejemplo señalemos la Real Orden que reiteraba la prohibición de las máscaras en 1773 (9), a la que el Cabildo respondió que en la ciudad de Cádiz no las había desde hacía algunos años. Sin embargo, podríamos sospechar que los Regidores no decían la verdad: Vittorio Alfieri relata en su libro La vita (1788) que en 1772 visitó Cádiz donde terminó "el Carnaval con bastante alegría".

(5) PORQUICHO, Isidoro: Cádiz, población y sociedad: 1597-1650. Las series parroquiales. Memoria de Licenciatura inédita.

(6) Archivo de Indias. Contratación 5.101. Debo esta referencia a la amabilidad del Dr. D. Antonio Domínguez Ortiz.

(7) Archivo Diocesano de Cádiz (A.D.C.), leg. 1813, Inmunidades 1670-78. Confer: Morgado García, art. cit.

(8) VICENS-VIVES, Jaime (dir): Historia de España y América. Social y económica. Vol. IV. Barcelona, 1974, p. 249. CARO BAROJA, Julio: op. cit., pp. 154-155.

(9) Archivo Municipal de Cádiz (A.M.C.). Actas capitulares, Cabildo 6 noviembre 1773. 
Nuevamente podemos ofrecer algún testimonio de lo que sucedía en los ambientes eclesiásticos, y comprobaremos que el desacato a las órdenes, tanto de la autoridad civil como de la jerarquía eclesiástica, era notable: en el convento de Santa María y en el de Nuestra Señora de Candelaria, se cometieron excesos - con el consiguiente escándalo de los fieles vecinos y de los que pasaban por las calles cercanas- en el Carnaval del año 1776. En el convento de la Candelaria, al parecer, la madre priora autorizó a las sirvientas a celebrar "diversiones domésticas" en los días de Carnaval, "siendo tanto el ruido y la algaraza", que se oía, no sólo en todos los rincones de la casa, sino también en la iglesia y en las calles y casas cercanas. El visitador -que no parece quedara muy convencido- exhortó a la priora a que desterrara del convento "el espíritu del siglo que es el que ha introducido tales diversiones en este tiempo tan misterioso". Pero -suponemos que consciente de lo difícil de su deseo- terminó ordenándole que "siempre que en él o en otro los permita, sea con la devida moderación y modestia de tal modo que no desdigan de la clausura religiosa..." (10).

Pese nuevas y reiteradas prohibiciones (11), las celebraciones carnavalescas lograron traspasar el umbral del siglo XIX, e incluso cuenta Antonio Alcalá Galiano en sus Memorias que, con gran lucimiento y recreo -y pese a las vicisitudes del asedio francés- el pueblo de Cádiz celebraba los días de Carnaval.

Durante el reinado de Fernando VII, el Carnaval no fue ajeno a las alternancias políticas del periodo, de forma que nos encontramos con que las prohibiciones o permisos para la celebración de la fiesta, siguen similares oscilaciones que las del gobierno fernandino (12). Así, durante el Sexenio Absoluto, los bandos expresan un tremendo rigor sancionador, como aquel del Marqués de Castelldorius de 20 de febrero de 1816, que trataba de prohibir totalmente las alegrías y diversiones del Carnaval (13).

La situación es muy diferente durante el Trienio Liberal, como demuestra el que en 1821 no sólo no se prohibieran las fiestas, sino

(10) A.D.C. Secretaría de Cámara, leg. 505. Confer Morgado García: art. cit. Véase también RAMOS SANTANA, Alberto: "Carnaval en el convento". $A B C$ de Sevilla del día 13 de febrero de 1988 .

(11) Podemos recordar, como ejemplo, la prohibición del gobernador de celebrar bailes en los teatros. A.M.C., Ac. Cap. Cab. 14 noviembre 1797.

(12) A este tema le hemos dedicado un breve estudio. Véase RAMOS SANTANA, Alberto. "El Carnaval, péndulo político del reinado de Fernando VII". Actas del Primer Seminario del Carnaval. Cádiz, 1986, pp. 15 a 29.

(13) Ibídem. 
que el gobernador D. Cayetano Valdés consintió el acuerdo votado por el Ayuntamiento para celebrar bailes públicos de máscaras, con la única limitación de que no se ofendieran las buenas costumbres (14).

Las restricciones volvieron en la llamada Década Ominosa, aunque con una cierta condescendencia. En este período podríamos hablar de precauciones, quizás exageradas, pero no de prohibiciones. Un claro ejemplo de lo que decimos es el Edicto del Gobernador don José Aymerich y Varas dado en Cádiz el 5 de febrero de 1828, y que transcribimos:

"EDICTO $=$ D. José Aymerich y Varas, Teniente General de los Reales Ejércitos, Gobernador Militar y Político de esta Plaza \&c. \&c. \&c.

Deseando contener los excesos que suelen cometerse en los días de Carnaval por algunas personas imprudentes, como contrarias a la buena policía y reglas prevenidas por los Autos de Buen Gobierno: MANDO, que se observen las disposiciones que se espresan en los artículos que siguen.

1. Toda persona de cualquiera clase, edad y estado que se ejercite en echar polvos, dejar caer guante alguno, disparar coetes (vulgarmente llamados triquitraques) contra lo que está prevenido en el Auto de Buen Gobierno, se la impondrá la pena que en el se espresa y además se procederá contra ella a lo que haya lugar, según su clase y estado, cuidando los padres de familia de contener a sus hijos, criados y dependientes de sus casas, para que no cometan semejantes escesos, de los que serán responsables.

2. ${ }^{\circ}$ Las que se entretuvieren en hacer daño a otras personas, poniéndoles estopa o cosa en que pueda recibir daño o mofa de los que lo ven, sufrirán la misma pena.

3.. Al vecino principal de la casa por la que se arrojase agua por las azoteas, ventanas o balcones se les exigirá 8 ducados de multa, quedando responsables a abonar los daños que se causen en los trages y ropas, si fuesen reclamados.

$\therefore \quad$ 4. Las gentes que anden por las calles (que no se permitirán reunidas en escesivo número de personas) irán con moderación, sin escandalizar con gritos ni voces, ni menos con palabras obscenas ofensivas a la Religión y contrarias a la tranquilidad públi$\mathrm{ca}$, absteniéndose de espresiones que puedan ser insultantes para

(14) Ibídem. 
los que transiten; los que faltaren al cumplimiento de esta providencia serán castigados según la gravedad de su esceso.

5. ․ En el teatro se guardará la mayor moderación, no arrojándose a los tablados dulces, confites, ni otra cosa que desazone a los actores ni concurrentes, faltando a la urbanidad y decoro que corresponde a los parajes públicos de un pueblo culto; en el concepto de que se procederá a la corrección del que contraviniere según las circunstancias del caso.

6.. Se prohiben absolutamente las máscaras, según las órdenes de S.M., y conforme también lo estás por las leyes del Reyno, que se observarán con toda puntualidad, bajo las penas que las mismas imponen; teniéndose por máscara la persona que con careta o sin ella transite con disfraces visibles por las calles, y que todo lo que no sea el trage de continuo uso en el individuo es disfraz o máscara. En tal concepto los infractores á esta orden serán castigados irremisiblemente con las penas que están marcadas por las leyes, y al efecto están dadas las oportunas para que sean arrestadas las personas que se encuentren por las calles con disfraz o máscara.

Encargo a las Autoridades y MANDO a los dependientes de este Gobierno, cuiden del exacto cumplimiento de cuanto queda prevenido; dándome éstos parte de las ocurrencias que sean dignas de mi noticia para proceder a lo que haya lugar. $\mathrm{Y}$ a fin de que llegue la noticia de todos lo he mandado imprimir y publicar. Cádiz 5 de febrero de 1828 = José Aymerich." (15)

A la hora de repasar este Edicto, que volvía por los fueros de cierta dureza, debemos recordar que Cádiz vivió entre 1823 y 1828 con un auténtico ejército de ocupación dentro de sus murallas -un importante contingente de Los Cien Mil Hijos de San Luis-, que propició un período represivo y de seguridad; así como no olvidar la fama de rígido del propio Aymerich.

Pero nuevamente surge la vitalidad del Carnaval, y el gobernador encontró respuesta a su Edicto en las propias páginas del Diario Mercantil de Cádiz donde publicó sus prevenciones; y las respuesta, como no podía ser de otra forma, satirizaba el contenido del Edicto gubernativo. Ya ha señalado Caro Baroja que "típicamente carnavales-

(15) Diario Mercantil de Cádiz, 6 de febrero de 1828, pp. 1 y 2. 
co era 'organizar' la sátira contra las autoridades e individuos de una manera muy definida, incluso escribiendo un texto" (16).

Lo que hemos considerado una auténtica respuesta a Aymerich, se publicó -como dijimos-, en el mismo periódico que el gobernador usó para difundir su Edicto, once días después, exactamente el domingo 17 de febrero de 1828, bajo el simple título de LETRILLA, y firmado solamente con una inicial: "P". Decía así:

\author{
"Déjame Antón, de consejos \\ que estoy sordo el Carnaval. \\ Escóndete en tu rincón \\ huyendo el guante y estopa, \\ que yo tengo ya la ropa \\ para hacer de Senescal; \\ y entre ópera y comedia \\ iré al bayle de Bachicha (17) \\ y llora tú mi desdicha \\ de estar sordo el Carnaval. \\ Dirás que soy cincuentón \\ que tengo mujer e hijos \\ y que danzo en regocijos \\ como la gente informal. \\ Pues en viendo una muchacha \\ la voy sirviendo de lego \\ que aunque sordo no estoy ciego \\ los días de Carnaval. \\ Mira Antón: Domingo, Lunes \\ y Martes son propios días \\ para andar en sinfonías \\ la persona más cabal. \\ Se me olvidaba decirte \\ que el oído se me empata \\ el Domingo de Piñata \\ lo mismo que el Carnaval. \\ Después vendrá el bacalao \\ escoltado de potages \\ y sirviéndole de pages
}

(16) CARO BAROJA, Julio: op. cit., p. 92.

(17) BACHICHA: Se refiere el autor a D. Agustín Remaggi, conocido director de bailes que tenía un local en la calle San Miguel, 23. Véase Diario Mercantil de Cádiz del día 15 de enero de 1837. 
mariscos de fé neutral.

Ya sano entonces mi oído

y curada mi locura

oiré la voz de mi cura

que no entendí el Carnaval."

Como más arriba indicábamos, creemos que la Letrilla no tiene desperdicio, y es un claro ejemplo de cómo se satirizaban las normas del poder en el tiempo de Carnaval. Un breve comentario puede completar nuestra visión. Los versos que pretendían burlarse del Edicto de Aymerich se publicaron en la misma página y prácticamente a la misma altura que las órdenes del gobernador. Y sus alusiones a aspectos concretos no deben dejar lugar a dudas de que se trata de una contestación al mandato gubernativo. Obsérvese que ante todo se resalta la sordera -temporal- del autor en tiempos de carnestolendas, como una auténtica fractura en la salud normal del individuo. Además, alude a algunos de los elementos y objetos de mofa que se citan expresamente en el Edicto de Aymerich: guante y estopa; y por si no fuera suficiente, el autor está dispuesto a disfrazarse de Senescal, es decir, de autoridad de la Corte. También las referencias a la edad y a la familia son una burla a las alusiones a las personas principales y responsables de las que habla el mandato de Aymerich.

Más adelante -y tras preferir los bailes populares de Bachicha a la ópera y la comedia (durante el Carnaval)-, marca los límites cronológicos de su sordera: Domingo, lunes, martes y domingo de Piñata. Transcurridas estas jornadas, la enfermedad se cura, el oído recobra su salud y vuelve a escuchar la voz de la Iglesia que le reclama a la moderación cuaresmal. Es el tiempo del ayuno y la abstinencia, del bacalao y los potages, aunque aún se permite el autor una leve ironía con los "mariscos de fe neutral".

Años más tarde, el propio Carnaval recordaba esta época de luchas contra sus enemigos cuando declaraba en El Comercio:

"Bien me burlé y rei, repuso el Carnaval, de los esbirros en aquella época de fanatismo: entonces, si bien no hubo bailes públicos, los particulares estaban más animados, y la misma prohibición avivava más el deseo y la afición a las máscaras, que en comparsa, corrían por las calles, cubriendo su disfraz y huyendo la persecusión de los alguaciles de la época" (18).

(18) "Un sueño de Carnaval". El Comercio, 13 de marzo de 1859. 